\title{
Development of methodological approaches to increase the efficiency of the investment activity of the enterprise
}

\author{
Roman Golov ${ }^{1, *}$, Dmitriy Spitsov ${ }^{2}$, Olga Yutkina $^{3}$ and Natalia Kazakova ${ }^{1}$ \\ ${ }^{1}$ Moscow Aviation Institute, Volokolamskoe highway, 4, 125993, Moscow, Russia \\ ${ }^{2}$ Moscow Institute of Architecture, Rozhdestvenka street 11, 107031, Moscow, Russia \\ ${ }^{3}$ Russian State University of Justice, 69, Novocheremushkinskaya street, 117418, Moscow, Russia
}

\begin{abstract}
The purpose of this study is to develop methods to improve the efficiency of development projects and attract investment in their implementation. The article analyzes the investment and construction activities of development companies in order to justify the expediency of using the portfolio approach and develop a system of criteria for their selection, study the existing sources of raising funds for investment and construction activities, and classify development companies depending on the way investment is attracted, assessment of the economic effect of investment and construction activities of development companies. The result of the study is the development of methodological approaches to increasing the efficiency of the portfolio of developer projects based on the proposed system of selection criteria for projects.
\end{abstract}

\section{Introduction}

Investment and construction activities of development companies are heterogeneous, because they use different ways to attract investment, namely: independent investment in their own development projects; mixed investment in the development project, both own funds and customer funds; implementation of a development project for third-party customers using their investments for a fee.

Grouping development companies in the manner of attracting investment in real estate development projects, we obtain a classification of developers.

Based on the portfolio approach proposed by the author for the selection and implementation of development projects, a new kind of development companies can be proposed: complex developers characterized by the combination of all ways of attracting investments into the portfolio of projects, including both own projects and projects for external customers (Table 1).

\footnotetext{
* Corresponding author: roman_golov@rambler.ru
} 
Table 1. Classification of developers by the method of attracting investments.

\begin{tabular}{|c|c|c|}
\hline Classification & Types of Developers & characteristic \\
\hline \multirow{4}{*}{ 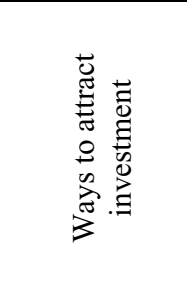 } & Developers-investors & Self-investment in own development projects \\
\hline & Mixed development & $\begin{array}{l}\text { Mixed investment in a development project, both } \\
\text { own funds and customer funds }\end{array}$ \\
\hline & Fee-development & $\begin{array}{l}\text { Realization of the development project for external } \\
\text { customers using their investments for a fee }\end{array}$ \\
\hline & $\begin{array}{l}\text { Complex } \\
\text { development }\end{array}$ & $\begin{array}{l}\text { Formation of the project portfolio and its } \\
\text { implementation on the basis of attracting } \\
\text { investments from all available sources }\end{array}$ \\
\hline
\end{tabular}

\section{Materials and Methods}

The proposed classification is an effective tool for analyzing and selecting the direction of development of investment and construction activities of development companies. A characteristic feature of the Russian real estate market is the presence of large developers, carrying out the entire cycle of operations from investing to the operation of real estate. In the changing market conditions, the preservation of this situation leads development companies to a shortage of investment resources. Companies need to develop and make management decisions that allow them to maintain their business. To meet this need, the author suggests an organizational mechanism for attracting investment, based on combining all available sources of investment for various projects that make up the portfolio (Figure 1) [1].

If we designate through Idi the volume of our own investments into independent and joint development projects, through Ici the volume of attracted investments for joint and custom development projects, then their sum will constitute the total need for investments for the portfolio of projects (I):

$$
I=\sum I d_{i}+\sum I c_{i}
$$

The most important moment in the formation of the volume of investment resources is the determination of their value. For this purpose, the methodology for determining the weighted average price of capital can be used: WACC. In this case, one should take into account the fact that the price of capital will only take place for own investment, since investments of third-party customers in the implementation of their projects have a zero value for the developer, which is reflected in the weighted average price of capital necessary to realize the entire portfolio of projects [2]. 


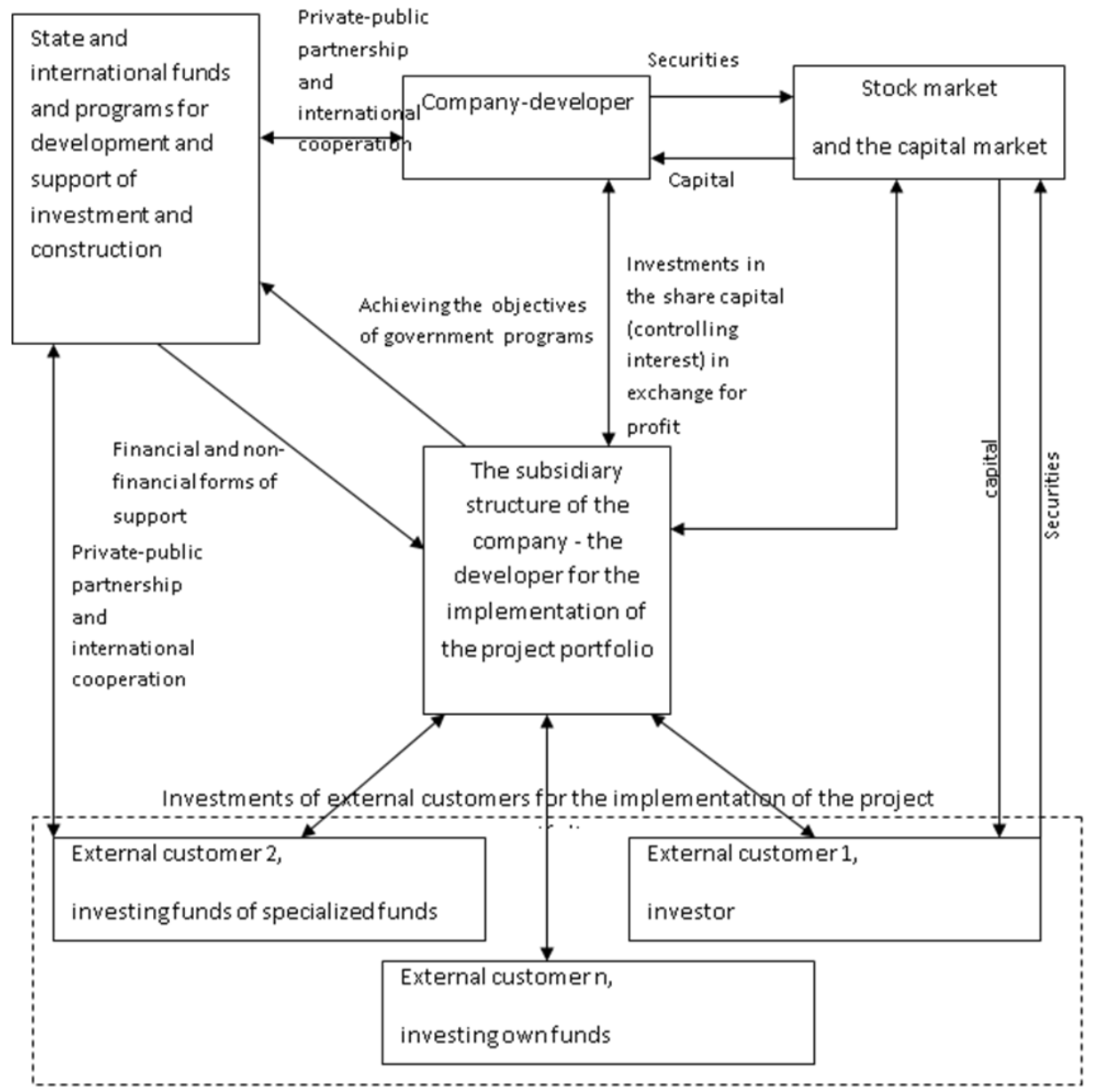

Fig. 1. Organizational mechanism for attracting investments in the portfolio of developer projects.

$$
\begin{aligned}
& W A C C p p=w_{d} \cdot W A C C d+w_{c} \cdot W A C C c= \\
& =w_{d} \cdot W A C C d+w_{c} \cdot 0 \%=w_{d} \cdot W A C C d,
\end{aligned}
$$

where WACCpp is the weighted average price of capital involved in the implementation of the entire portfolio of projects; WACCd is the weighted average price of the developer's capital; wd - the share of the developer's own investments in the total investment needs for the project portfolio; WACCc - weighted average price of capital of third-party customers; $\mathrm{wc}$ is the share of investments of third-party customers in the total investment needs for the project portfolio [3].

Therefore, WACCpp can change in the interval [0; WACCd]. The expediency of using the developed organizational mechanism for attracting investments in the implementation of the portfolio of developer projects can be justified by, first, improving the efficiency of investment and construction activities of the developer by combining cash flows as a return on their own investments and as fees for services for implementing projects for external customers . Secondly, the opportunity to use capital to implement a portfolio of projects 
with zero cost for a developer, provided that only external projects are included in the portfolio [4].

\section{Results}

Having formed a portfolio of projects based on the proposed system of criteria for selecting projects and the volume of investments required for its implementation from various sources, one can proceed to an assessment of the economic efficiency of implementing a portfolio of developer projects. Based on the methodology of project analysis recognized by specialists and widely used in business practice, the author proposes an algorithm for assessing the economic efficiency of a portfolio of projects, including the calculation of generally accepted indicators and the author's estimate of the commissioner's commission for the implementation of projects of external customers, which allows to ensure that the methodology for assessing the economic efficiency of investment projects with a portfolio of projects [5].

In developing the algorithm for assessing the economic efficiency of the project portfolio, the author proceeded from the premise that, other things being equal, the developer has the right to additional compensation if the market value of the realized portfolio exceeds the amount invested, adjusted for the average market or industry average profit rate. In this case, the major motivation of the developer will not be an increase in the gross volume of investments in the portfolio of projects to be implemented in order to increase the commission fee at a fixed commission percentage of the volume of investments being mastered, but to increase the market value of the portfolio of projects or to achieve a synergistic effect from combining individual projects into a single portfolio. This approach works if the commission percentage is defined as the difference between the internal rate of return of the portfolio of projects and the value of invested capital determined by the customer.

The proposed algorithm for assessing the economic efficiency of the developer's portfolio of projects is implemented in several stages. At the first stage, the developer forms a portfolio of projects in accordance with the approach presented in Figure 1. The resulting portfolio of projects is characterized by an acceptable level of investment risk for the developer, the maximum value of economic added value, the increased added market value and compliance with the constraints imposed by the company's development strategy. The importance of this stage is that the professional efforts of the developer should focus on maximizing the market value of the project portfolio [5].

At the second stage, we determine the structure and price of invested capital. Since the price of capital invested by external customers for the developer is zero, here we determine only the price of the developer's own invested capital. For this, the WACC methodology is used. First, based on the cost approach, determines the overall need for investment (I) for the implementation of the project portfolio. Secondly, the shares of own investments and investments of the customer are allocated (wd, wc). Third, we determine the value of our own investment resources (WACCd) in accordance with the WACC methodology. Fourth, in accordance with formula (2), we determine the weighted average price of capital involved in the implementation of the entire portfolio of projects (WACCpp).

The third stage: based on the analysis of the cash flow arising in connection with the implementation of custom projects included in the portfolio of projects, we determine the internal rate of return for external customers projects (IRRc). Cash flow is formed from the need for investment, determined on the basis of the cost approach, and the market value of real estate objects created during the implementation of the projects of the customer.

Fourth stage: determine the percentage of commission of the developer $(\mathrm{K} \%)$. 


$$
\mathrm{IRRc}-\mathrm{Ec}=\mathrm{K} \%
$$

where $\mathrm{Ec}$ is the discount rate established by the customer of the development project.

If $\mathrm{K} \%$ takes a negative value or is equal to zero, then the project portfolio is recognized as economically inefficient and its implementation is not expedient.

If $\mathrm{K} \%$ assumes a positive value, then the project portfolio is recognized as cost-effective and is accepted for implementation. In this case, the developer is interested in including in the portfolio of projects that increase its market value in order to increase the value of commission interest (Figure 2).

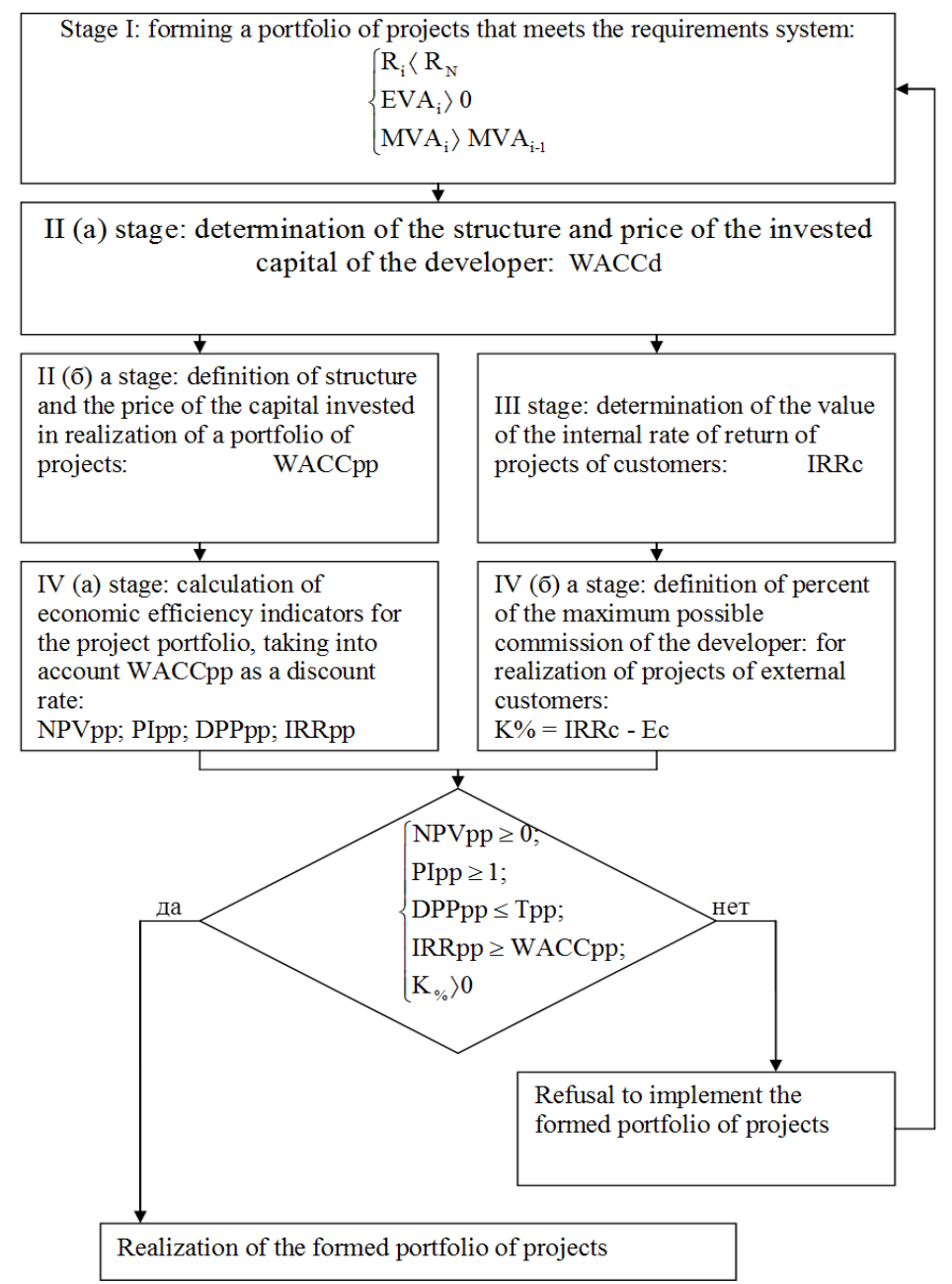

Fig. 2. Algorithm for assessing the economic efficiency of the developer's portfolio of projects.

The developer's commission for the implementation of external customers' projects was introduced into the mathematical model of assessing the developer's economic effect from the portfolio of projects, which makes it compatible with the project portfolio formed on the basis of the project selection criteria proposed by the author.

The model for assessing the economic effect of the implementation of the management mechanism of the investment and construction activities of a development company is based on combining the effect of its own invested capital and the effect of the developer's 
professional activity, i.e. the developer's commission for the implementation of the project portfolio.

$$
\begin{gathered}
\mathrm{Ed}=[\mathrm{MVd}-\mathrm{Id} *(1+\mathrm{WACCd})]+\mathrm{MVc} * \mathrm{~K} \%=[\mathrm{MVd}-\mathrm{Id} *(1+\mathrm{WACCd})]+ \\
{[\mathrm{MVc} *(\operatorname{IRRc}-\mathrm{Ec})]}
\end{gathered}
$$

where Ed - the economic effect of the developer on the implementation of the management mechanism of investment and construction activities; MVd - the market value of real estate objects obtained during the implementation of independent projects of the developer; MVc - the market value of real estate received during the implementation of projects of external customers.

The reserve of increasing the economic efficiency of the developer is concentrated in the indicator "commission percentage", which can be increased due to an increase in the market value of the portfolio of projects without increasing the need for investment in implementing this portfolio of projects.

Application of the approaches proposed by the author to the formation of a portfolio of developer projects and attracting investments in its implementation leads to ambiguous consequences, in particular, the resulting project portfolios can be characterized by different proportions of their own developers 'projects and external customers' projects. This makes it possible to apply the scenario approach to proposing recommendations on the behavior of development companies in different situations.

The author developed an algorithm for the optimal use of the proposed tools to improve the efficiency of investment and construction activities of the developer based on the scenario approach, depending on the value of the indicator of the weighted average price of capital invested in the implementation of the project portfolio (Figure 3). Depending on the value that the WACCpp indicator takes, three situations can be identified. The first situation: WACCpp = WACCd, which is typical for the situation when the portfolio of projects is fully formed from projects, the investments into which are entirely carried out by the developer. The effectiveness of investment and construction activities in this case depends on the ability of the developer to attract inexpensive investment resources from both own and borrowed capital, the developer's income will consist of cash flow from the implementation of their own projects:

$$
\mathrm{Ed}=\mathrm{MVd}-\mathrm{Id} *(1+\mathrm{WACCd})
$$

The sources of increasing the effectiveness of the investment and construction activities of the developer, as can clearly be seen from the formula (5), are: firstly, an increase in the market value of own projects, which is facilitated by the use of the proposed model for the formation of a portfolio of projects; secondly, a decrease in the weighted average price of capital involved in the implementation of investment projects. WACCd depends on market factors, therefore, the developer can not directly influence them, therefore, the developer is recommended to monitor the situation on the capital market in order to form the optimal investment structure from the point of view of value; thirdly, a reduction in the need for investment. The need for investments in the implementation of development projects is determined on the basis of a cost approach, taking into account market data on the cost of necessary resources. The use of new world technologies and own innovations along with building transparent relations with local authorities will reduce the overall need for investment. 


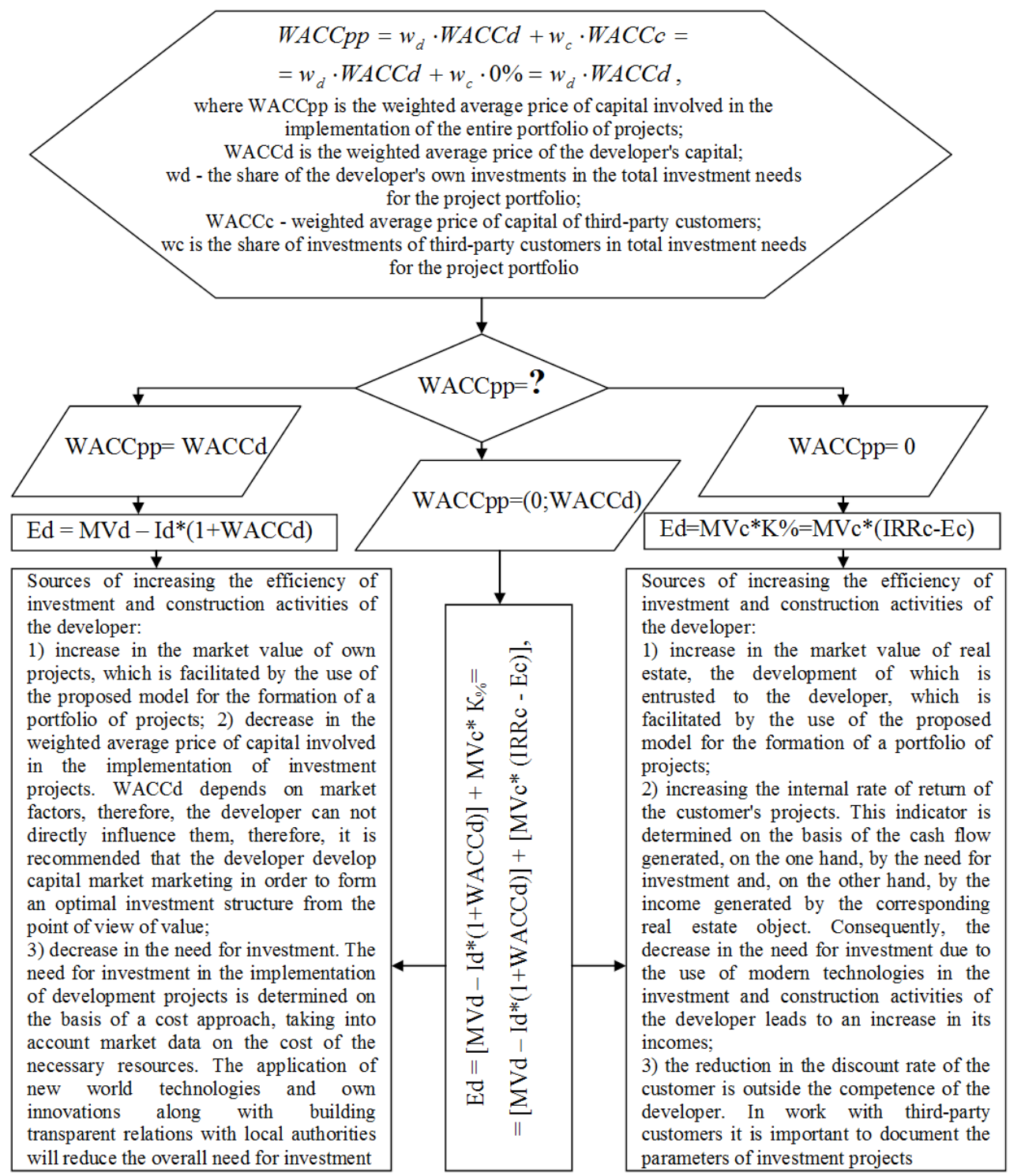

Fig. 3. Algorithm for the optimal use of proposed tools to improve the efficiency of investment and construction activities of the developer.

The second situation: WACCpp $=0$, which is typical for the situation when the portfolio of projects is fully formed from projects, investments in which are carried out only by thirdparty customers. The effectiveness of investment and construction activities in this case depends on the developer's ability to understand and offer the customer the best way to meet his needs and maximize the market value of the property entrusted to the developer. The developer's income will be formed from the commission for the implementation of development projects for third-party customers:

$$
\mathrm{Ed}=\mathrm{MVc} * \mathrm{~K} \%=\mathrm{MVc} *(\mathrm{IRRc}-\mathrm{Ec}) .
$$

The sources of increasing the effectiveness of the investment and construction activities of the developer, as can be seen from the formulas (6), are: firstly, an increase in the market 
value of real estate objects, the development of which is assigned to the developer, which is facilitated by the use of the proposed portfolio model; secondly, an increase in the internal rate of return of the customer's projects. This indicator is determined on the basis of the cash flow generated, on the one hand, by the volume of the demand for investments and, on the other hand, by the income generated by the corresponding real estate object. Consequently, the decrease in the need for investment due to the use of modern technologies in the investment and construction activities of the developer leads to an increase in its revenues; Third, the reduction in the customer's discount rate is beyond the competence of the developer.

The third situation: WACCpp belongs to the interval (0; WACCd), which is typical for the situation when the portfolio of projects includes both the developer's own projects and projects for third-party customers. In this case, the income of the developer will be determined by the formula (4), and to improve the efficiency of investment and construction activities, it is possible to recommend the implementation of the activities planned for situations 1 and 2 .

\section{Conclusion}

Based on the analysis of sources of capital, a classification of development companies was developed depending on the way of attracting investments and a type of integrated development characterized by attracting investments in the portfolio of projects from all available sources was proposed. To create a system of relationships between participants in this investment process, an organizational mechanism has been developed, the main elements of which are the several blocks described in this article. Further, based on the scenario approach, an algorithm for the optimal use of the proposed tools to improve the efficiency of investment and construction activities of the developer, depending on the value of the index of the weighted average price of capital invested in the implementation of the project portfolio, was developed.

\section{References}

1. A.D. Ishkov, T.N. Magera. Procedia Engineering 117, 148-153 (2015)

2. Y.V. Larionova, S.A. Pavlova, Life Science Journal 12, 650 (2014)

3. Y. Panibratov, A. Larionov, Applied Mechanics and Materials 8, 725-726 (2015)

4. I.V. Ilin, A.I. Levina, O.Yu. Iliashenko, MATEC Web of Conf. 86, 05028 (2016) doi: $10.1051 /$ matecconf $/ 20168605028$

5. O. Kalinina, O. Valebnikova, Advances in Intelligent Systems and Computing 692, 1315-1322 (2018) doi: 10.1007/978-3-319-70987-1_139

6. A. Jones, G. Fallon, R. Golov, European Business Review 12(4), 187-197, doi. $\underline{10.1108 / 09555340010336871}$ 